J. Lake Sci. (湖泊科学), 2015, 27(1): 183-189

http://www. jlakes. org. E-mail : jlakes@niglas.ac.cn

(C) 2015 by Journal of Lake Sciences

\title{
巴丹吉林沙漠盐湖跃层对地下淡水排泄的指示作用"
}

\author{
陈添斐 ${ }^{1}$, 王旭升 ${ }^{2 * *}$, 胡晓农 $^{1}$, 卢会婷 $^{2}$, 巩艳萍 ${ }^{2}$ \\ (1:中国地质大学(北京) 地下水循环与环境演化教育部重点实验室,北京 100083) \\ (2: 中国地质大学(北京)水资源与环境学院,北京 100083)
}

摘 要: 位于阿拉善高原的巴丹吉林沙漠分布有大量盐湖. 为揭示盐湖分层特征以及地下水对盐湖水体的影响,选取沙 漠腹地的第二大盐湖——苏木巴润吉林, 对 9 月份湖水的温度和电导率剖面进行了观测. 结果表明, 尽管所测盐湖宽深比 大于 90 , 还是存在温跃层. 温跃层的矿化度 (TDS) 为 $60 \sim 160 \mathrm{~g} / \mathrm{L}$, 靠近湖底的水体存在 TDS 低值异常区, 形成化跃层, 推 测为地下淡水集中排泄所致. 这种湖底泉在其它较浅的盐湖水体中也存在,说明深、浅层地下水对盐湖水分及盐分都有 贡献. 温跃层水温随深度的变化近似符合静止水体的热传导规律,并没有受到地下水排泄热量的显著影响. 研究区盐湖 跃层的季节性变化还有待进一步研究.

关键词: 温度; 矿化度;地下水;巴丹吉林沙漠;苏木巴润吉林

\section{Clines in salt lakes in the Badain Jaran Desert and their significances in indicating fresh groundwater discharge}

\author{
CHEN Tianfei ${ }^{1}$, WANG Xusheng ${ }^{2}$, HU Xiaonong $^{1}$, LU Huiting ${ }^{2} \&$ GONG Yanping ${ }^{2}$ \\ (1: Ministry of Education Key Laboratory of Groundwater Circulation and Evolution, China University of Geosciences, Beijing \\ 100083, P. R. China) \\ (2: School of Water Resources and Environment, China University of Geosciences, Beijing 100083, P. R. China)
}

\begin{abstract}
A number of salt lakes exist in the Badain Jaran Desert that located in the Alxa Plateau, China. To reveal the stratification characteristics of salt lake water and the impacts of groundwater to the lakes, a survey of the depth-dependent temperature and electric conductivity in September was carried out in the second largest salt lake: the Sumu Barun Jaran. Thermocline is observed even though the lake has a big wide/deep ratio that is higher than 90 . The salinity (TDS) varies from 60 to $160 \mathrm{~g} / \mathrm{L}$, exhibits a relatively strong spatial variation. Abnormally low TDS zones exist near the lake bottom, forming chemocline in the themocline, which is considered to be influenced by concentrated discharge of fresh groundwater. This type of sub-lake springs have also been observed beneath shallow water bodies in other salt lakes, showing that both shallow and deep groundwater contribute water and salts into the lakes. Variation of temperature versus depth in the thermocline approximately satisfies the heat transfer in a static water body, is not significantly influenced by heat transfer from groundwater discharge. Further investigations are required for the seasonal variation patterns.
\end{abstract}

Keywords: Temperature; salinity; groundwater; Badain Jaran Desert; Sumu Barun Jaran

巴丹吉林沙漠位于阿拉善高原, 面积约 $4.92 \times 10^{4} \mathrm{~km}^{2}$, 是我国第三大沙漠, 以高大的沙山和星罗棋布的 湖泊闻名于世. 沙山主要集中在沙漠中部,一般高 $200 \sim 300 \mathrm{~m}$,最高可达 500 余米. 伴随高大沙丘,沙漠内还 发育 100 多个湖泊 ${ }^{[1]}$, 面积多为 $0.1 \sim 1.0 \mathrm{~km}^{2}$, 接近或超过 $1.0 \mathrm{~km}^{2}$ 的有 5 个湖, 分别为诺尔图、苏木巴润吉 林、呼和吉林、音德尔图和巴丹 ${ }^{[2-3]}$. 巴丹吉林沙漠属于极度干旱区,多年平均降水量约为 $100 \mathrm{~mm}$, 而多年平

* 国家自然科学基金重大研究计划项目 (91125024) 和核设施退役及放射性废物治理项目 (科工二司 [2013] 727 号) 联合资助. 2014-02-24 收稿;2014-06-12 收修改稿. 陈添斐(1987 ), 女,博士研究生;E-mail : chentianfei1987@ 126. com.

** 通信作者;E-mail:wxsh@ cugb. edu. cn. 
均蒸发量大于 $3000 \mathrm{~mm}^{[4]}$. 高大沙丘与湖泊共存的奇特景观引起了国内外学者的关注. 从水均衡角度来看, 湖面接受的降水量远小于湖泊蒸发耗水量, 而且沙漠几乎不存在地表径流, 因此地下水就成为湖水的主要 补给来源. 然而, 由于缺乏观测资料, 人们尚不了解这些沙漠湖泊的水体结构特性, 也不清楚沙漠地下水如 何影响这些湖泊.

沙漠湖泊理化特性的空间分布不仅是对湖泊演变状态最直观的表达, 而且对地下水的排泄方式具有一 定的指示意义. 巴丹吉林沙漠湖水的矿化度变化范围很大, 介于 $1 \sim 400 \mathrm{~g} / \mathrm{L}$ 之间 ${ }^{[3]}$. 在水化学性质已知的湖 泊中,一半以上矿化度大于 $35 \mathrm{~g} / \mathrm{L}$, 属于盐湖. 因此, 巴丹吉林沙漠湖水的来源和变化特征成为研究热点, 现 有研究多集中于讨论沙漠水分的宏观来源 ${ }^{[4-11]}$, 少数研究湖泊群水化学空间分布特征 ${ }^{[12]}$ 以及湖泊数量、面 积的季节性变化 ${ }^{[13-14]}$. 相对而言, 典型湖泊水体空间特性及地下水排泄方式的观测研究较少. 最近, 陆莹 等 ${ }^{[15]}$ 基于分层采样资料, 初步分析了诺尔图理化剖面的季节性变化, 但没有确定地下水的排泄方式. 本文选 择巴丹吉林沙漠的第二大盐湖一一苏木巴润吉林, 进行剖面特征的观测, 发现了温跃层和盐跃层, 其中盐跃 层对地下淡水排泄具有一定的指示作用.

\section{1 数据来源与研究方法}

\section{1 观测方法}

苏木巴润吉林位于巴丹吉林沙漠的东南部 (39 $46^{\prime} \sim 39^{\circ} 48^{\prime} \mathrm{N}, 102^{\circ} 24^{\prime} \sim 102^{\circ} 26^{\prime} \mathrm{E}$ ) (图 1 ), 面积 $1.24 \mathrm{~km}^{2}$. 湖周围为沼泽化草甸, 植物低矮而密集, 向外是盐生化草甸, 长有大片的芦苇和菆菆草, 形成典型 的沙漠湿地景观. 2012 年 9 月, 笔者在苏木巴润吉林的北部选取一个控制性剖面线,对湖水不同深度的温度 和电导率进行了测定. 所采用的测量仪器为加拿大 Solinst 公司生产的 107 型 TLC 温盐深计, 可同时测定水 位、水温和电导率, 水位通过绳长确定, 温度的量程为 $-15 \sim 50^{\circ} \mathrm{C}$ 、精度为 $\pm 0.3^{\circ} \mathrm{C}$. TLC 仪的表计最大电导 率可以达到 $999.9 \mathrm{mS} / \mathrm{cm}$, 仪器使用手册中指出电导率在 $0 \sim 80 \mathrm{mS} / \mathrm{cm}$ 范围的校准试验表明精度可以达到 $\pm 2 \%$.

本次测量共布设 22 个测点 (图 1), 每个测点理化性质随深度的变化通过从湖面至湖底依次进行观测, 即每隔 $1 \mathrm{~m}$ 测定 1 次温度和电导率, 遇到观测数据快速变化的深度段, 测试间隔减小为 $0.5 \mathrm{~m}$. 每测完 1 个 点, 将承重铁环绑在一根长绳上, 让铁环沉人湖底, 再在绳子的另一端系上一个浮球作为该点的标志, 为控 制测点距离提供参照物.

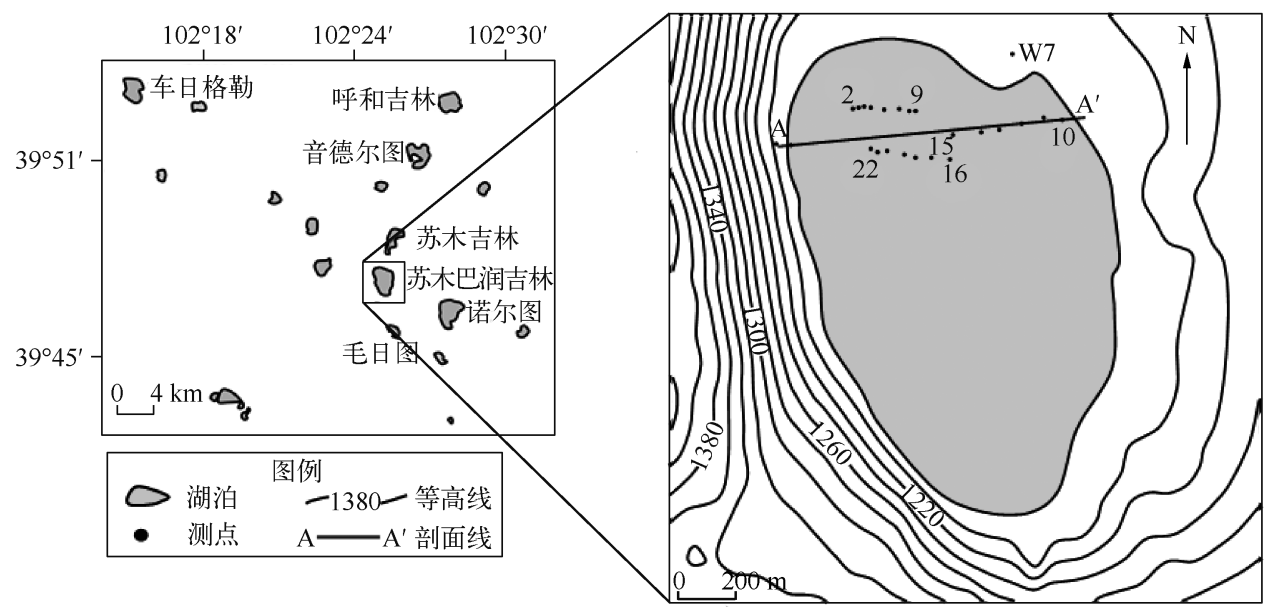

图 1 研究区和测点位置 (W7 为地下水观测孔)

Fig. 1 Location of study area and observation points ( W7 is a groundwater observation well)

2012 年 9 月上旬在盐湖东北部的沙丘上钻取了一个地下水观测孔, 即图 1 中的 W7. 该孔深度为 $16.3 \mathrm{~m}$, 
观测到地下水埋深 $5.5 \mathrm{~m}$, 地下水位比湖面高出约 $1.9 \mathrm{~m}$. 在 $\mathrm{W} 7$ 的水位下安装了斯伦贝谢水务公司出产的水 温-水压传感器 (MiniDiver), 监测地下水温度和水位的变化. MiniDiver 的温度量程为 $0 \sim 40^{\circ} \mathrm{C}$, 精度为 $\pm 0.1^{\circ} \mathrm{C}$.

\section{2 数据处理}

观测结果表明不同深度的湖水温度存在一定的差异. 由于水体的电导率受温度影响较大, 为换算成矿 化度, 需将不同温度下测定的电导率统一转化为标准温度下 $\left(25^{\circ} \mathrm{C}\right)$ 的电导率. 一般地, 温度与电导率呈非线 性关系, 但当温度变化范围较小时接近线性相关, 常采用如下形式的线性公式 ${ }^{[16]}$ :

$$
E C_{25}=E C_{\mathrm{t}} /[1+a(T-25)]
$$

式中, $E C_{t}$ 为测定温度下的电导率 $(\mathrm{mS} / \mathrm{cm}), E C_{25}$ 为 $25^{\circ} \mathrm{C}$ 下的电导率 $(\mathrm{mS} / \mathrm{cm}), a$ 为温度补偿因子 $\left({ }^{\circ} \mathrm{C}^{-1}\right), T$ 为测定温度 $\left({ }^{\circ} \mathrm{C}\right)$. 为了确定温度补偿因子, 根据野外实测的电导率值和温度值的范围, 自主配比 $\mathrm{NaCl}$ 溶液, 采用同一个 TLC 温盐深计进行校正试验, 测定各个温度对应的电导率, 绘制电导率与温度的关系曲线. 由此 确定 $a$ 为 $0.0194^{\circ} \mathrm{C}^{-1}$, 该值与前人研究盐湖时提供的经验数值一致 ${ }^{[17]}$, 说明校正方法可靠.

矿化度 (TDS) 与标准温度下 $\left(25^{\circ} \mathrm{C}\right)$ 的电导率近似呈正比关系 ${ }^{[17]}$, 可以用公式表示为:

$$
[T D S]=E C_{25} / k
$$

式中, 系数 $k$ 与温度无关. 根据苏木巴润吉林表层湖水的实测矿化度 $(128 \mathrm{~g} / \mathrm{L})$ 和 $25^{\circ} \mathrm{C}$ 时实测电导率值 $(208 \mathrm{mS} / \mathrm{cm})$ 确定系数 $k$ 为 $1.625(\mathrm{mS} / \mathrm{cm}) /(\mathrm{g} / \mathrm{L})$. 利用这个参数值即可将标准温度下 $\left(25^{\circ} \mathrm{C}\right)$ 的电导率数 值转化为对应的矿化度, 具有相对意义. 笔者利用 $\mathrm{NaCl}$ 配置高矿化度溶液对 TLC 仪所测电导率的转换精度 进行了校核,确定上述转换方法的相对误差在 $6 \%$ 以内,是可以接受的.

\section{2 结果与分析}

\section{1 温度剖面特征}

根据胡汝骥等的研究 ${ }^{[18-19]}$, 干旱区湖泊的宽度往往比深度大几个甚至数十个数量级, 呈浅碟状, 在风生 湖流的作用下, 湖泊水体能够得到充分混合, 导致垂向上各个深度的水温、矿化度、水流速率等理化特性具 有很强的均匀性, 几乎没有分层现象. 本研究在苏木巴润吉林测量的断面也呈现干旱区湖盆常见的浅碟形, 湖水最深为 $11.1 \mathrm{~m}$, 宽为 $1025 \mathrm{~m}$, 宽深比达到 93 . 那么,这个盐湖是否也不存在分层现象呢?

对于上述问题, 观测结果给出了否定的答案. 苏木巴润吉林在 9 月份的水温随深度的增加而减小, 而水 温的横向变化很小,具有正温层分布特征 (图 2). 当水深小于 $6 \mathrm{~m}$ 时,垂向温度梯度很小,水温介于 $22.0 \sim$ $24.0^{\circ} \mathrm{C}$ 之间, 几乎均匀分布, 与湖面气温基本一致. 这是由于浅层湖水受到风、太阳辐射等驱动产生对流, 导 致水体混合温度趋于均匀分布. 据此, 该盐湖 9 月份的混合层 (图 2 中的 $\mathrm{A}$ 层) 厚度约为 $6 \mathrm{~m}$. 当水深大于 $6 \mathrm{~m}$ 时, 横向的温度梯度一般仍然小于 $0.01^{\circ} \mathrm{C} / \mathrm{m}$, 仅在靠近湖的东岸处横向温度梯度可以达到 $0.04{ }^{\circ} \mathrm{C} / \mathrm{m}$. 而在垂直方向上, 混合层以下的水温随深度的增加迅速减小, 温度梯度均大于 $0.2^{\circ} \mathrm{C} / \mathrm{m}$, 平均温度梯度为 $3.5^{\circ} \mathrm{C} / \mathrm{m}$, 属于典型的温跃层 ${ }^{[20-21]}$. 这一温跃层的厚度近似有 $5 \mathrm{~m}$ (图 2 中的 B 层). 温跃层水体几乎静止, 热 量扩散慢,从而形成较大的温度梯度.

\section{2 矿化度的剖面分布特征}

总体而言, 苏木巴润吉林矿化度垂向上的分层现象不如温度的分层现象明显, 但也有一定的分层特征 (图 2). 当水深小于 $6 \mathrm{~m}$ 时,处于混合层内,矿化度分布比较均匀,介于 $120 \sim 140 \mathrm{~g} / \mathrm{L}$ 之间. 这是由于该层存 在强烈的混合作用导致湖水的化学性质比较均一. 当水深大于 $6 \mathrm{~m}$ 时, 湖水盐度的空间变异性增强,矿化度 介于 $60 \sim 160 \mathrm{~g} / \mathrm{L}$ 之间, 其横向和垂向的变化都比混合层显著. 随着深度增加, 矿化度总体发生 2 次大的突 变:一次是在水深为 $7 \mathrm{~m}$ 时, 矿化度骤降 $10 \sim 20 \mathrm{~g} / \mathrm{L}$; 另一次则是在靠近湖底时, 矿化度急剧下降 $30 \sim$ $90 \mathrm{~g} / \mathrm{L}$. 在横向上,矿化度的变化梯度小于垂向梯度. 在距西岸 $837 \mathrm{~m}$ 处, 矿化度随深度先增大至 $163 \mathrm{~g} / \mathrm{L}$, 后 减小. 在距西岸 $913 \mathrm{~m}$ 处, 温跃层矿化度随相对深度的增加而降低, 靠近湖底时矿化度异常低, 约为 $68 \mathrm{~g} / \mathrm{L}$. 这说明温跃层的矿化度分布比温度分布具有更强烈的不均匀性.

为了更宏观地判断湖水盐分的空间变化趋势, 绘制了矿化度随深度变化的散点图 (图 3). 可以看出, 当 

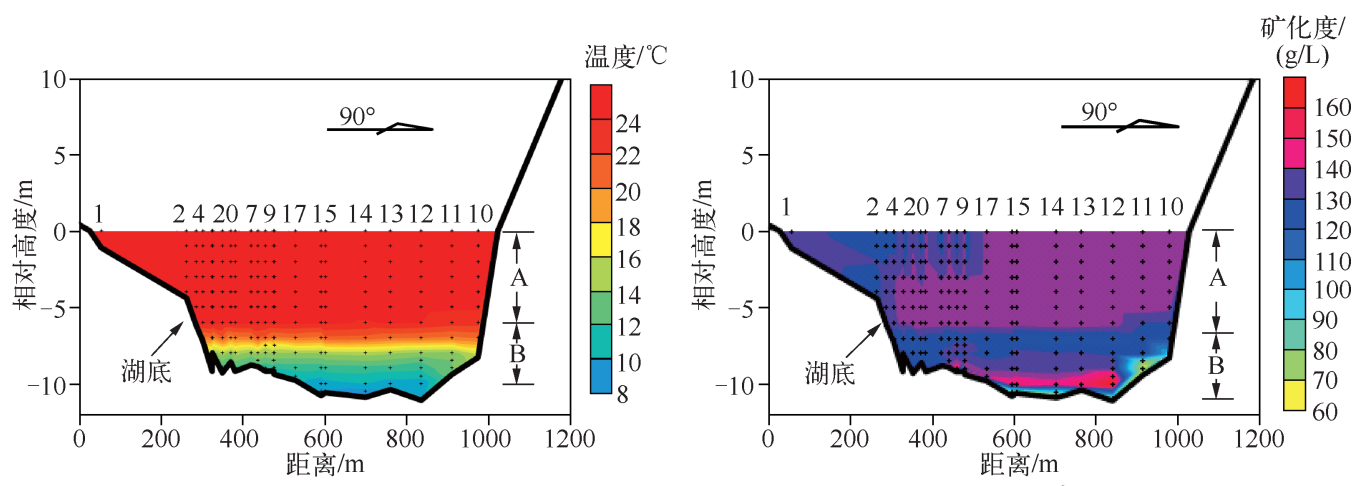

图 2 苏木巴润吉林温度和矿化度的剖面分布图 (A 为混合层, $\mathrm{B}$ 为温跃层)

Fig. 2 Temperature and salinity profiles of Sumu Barun Jaran (zones $\mathrm{A}$ and $\mathrm{B}$ are the mixing layer and thermocline, respectively)

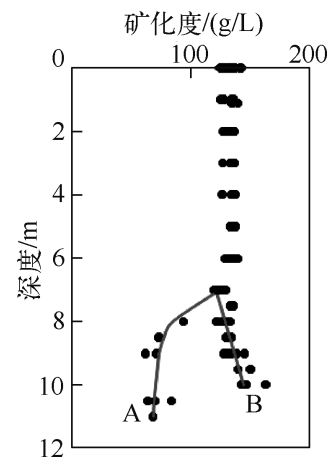

图 3 苏木巴润吉林矿化度随深度变化 的散点图 ( $\mathrm{A}$ 和 $\mathrm{B}$ 为 2 条趋势线)

Fig. 3 Scatter diagram of salinity-depth trends in Sumu Barun Jaran( A and B are two trend curves)

水深小于 $7 \mathrm{~m}$ 时, 矿化度随深度的变化不明显 (平均值为 130 $\mathrm{g} / \mathrm{L}$ ), 且同一深度处矿化度的最大值与最小值相差不超过 10 $\mathrm{g} / \mathrm{L}$. 当水深大于 $7 \mathrm{~m}$ 时, 矿化度随深度的变化表现出 2 种相 反的趋势: 一种随深度的增加近似呈指数趋势减少, 最小 $\operatorname{TDS}$ 接近 $60 \mathrm{~g} / \mathrm{L}$; 另一种则随深度的增加近似呈线性趋势增 加, 最大 TDS 接近 $160 \mathrm{~g} / \mathrm{L}$. 这 2 种变化趋势可分别拟合为图 3 中的 $A 、 B$ 线, 即:

$$
\begin{aligned}
\operatorname{TDS}(z)= & 68.35+55.9 \exp [-1.21(z-7)], z>7 \mathrm{~m}(3) \\
& \operatorname{TDS}(z)=7.67 z+67.8, z>7 \mathrm{~m}
\end{aligned}
$$

拟合的相关系数 $R^{2}$ 值分别为 0.84 和 0.54 . 推测 $\mathrm{B}$ 线为一般 情况下湖水盐分剖面, 即矿化度和密度大的湖水受重力作用 下沉,而矿化度和密度相对较小的湖水浮在浅层. B 线的情 况主要出现在湖的西半部分. 相比之下, A 线与 B 线的趋势 相反, 推测是受到了地下水集中排泄区的影响, 将在 3.3 节 进行详细讨论.

\section{3 讨论}

\section{1 形成混合层的动力条件}

在苏木巴润吉林观测的 9 月份水温和矿化度剖面显示了沙漠盐湖混合层的存在. 混合层内湖水具有较 强的动力条件, 即湖水在风、密度差异、太阳辐射等驱动下发生强烈的对流和混合作用, 导致湖水的理化性 质趋于均一. 混合层的厚度并非恒定的, 而是会发生季节性的变化, 并对盐分的混合过程产生影响. 陆䒯 等 ${ }^{[15]}$ 在诺尔图的观测表明常年情况下混合层的厚度为 $4 \sim 9 \mathrm{~m}$, 少数情况下出现整体混合. 苏木巴润吉林应 该也有类似情况. 这说明即使是宽深比很大的浅碟型湖泊, 在条件合适的情况下, 也可以出现混合层的常态 化. 研究区盛行西北风和西风, 年平均风速大于 $2 \mathrm{~m} / \mathrm{s}$, 对驱动湖水对流、形成整体混合是有利的. 然而, 巴丹 吉林沙漠湖泊的周围存在高大沙山, 对风场有扰动、削弱作用, 导致湖面的风力并不像平原区那么显著, 限 制了混合层向下的扩展. 受观测计划和野外条件的限制, 本研究只获得 9 月份的情况, 未能捕捉到不同季节 混合层的变化. 湖水混合层形成的具体动力学特征和变化规律还需要开展进一步观测研究.

\section{2 温跃层是否指示地下水排泄}

本文所研究的盐湖位于封闭盆地, 不发育地表水, 因此地下水是湖泊最主要的水分来源. 那么, 湖泊水 
温剖面特征是否能够反映地下水向湖泊的排泄方式呢?

观测结果表明苏木巴润吉林 9 月份的温跃层大概从 $6 \mathrm{~m}$ 深度开始, 温度从 $24^{\circ} \mathrm{C}$ 左右下降到 $8^{\circ} \mathrm{C}$ 左右, 温 差达 $16^{\circ} \mathrm{C}$, 在湖底形成低温区. 2012 年 9 月至 2013 年 4 月期间, W7 孔观测到地下水的温度在 $15.0 \sim$ $17.5^{\circ} \mathrm{C}$ 之间变化. 这说明盐湖周围地下水的温度介于 9 月份盐湖底部温度和混合层温度之间, 因此湖底的 低温区不能完全解释为地下水排泄的作用.

苏木巴润吉林温跃层的形成很可能只是湖泊水体响应气温变化发生热运移的结果. 为此, 在忽略地下 水排泄作用的前提下进行了理论推测. 假设混合层的水温与日平均气温保持一致,而温跃层水体保持静止 状态, 则温跃层的垂向热传导可以近似用扩散方程描述 ${ }^{[22]}$. 如果混合层温度 (假设与气温一致) 季节性波动 采用正弦函数表示, 同时忽略地下水排泄引起的热量传递, 把温跃层的下边界假设为绝热边界, 则温度在温 跃层的变化可以采用以下解析解 ${ }^{[22]}$ 表示:

$$
T(z, t)=T_{0}+A \exp \left(-\sqrt{\frac{\omega}{2 a}} z\right) \sin \left[\omega\left(t-t_{0}\right)-\sqrt{\frac{\omega}{2 a}} z\right]
$$

式中, $T(z, t)$ 为温度分布函数; $z$ 为从温跃层顶面算起的深度 $(L) ; t$ 为时间 $(T) ; T_{0}$ 为多年平均气温 $\left({ }^{\circ} \mathrm{C}\right) ; A$ 为气温振幅的多年平均值 $\left({ }^{\circ} \mathrm{C}\right) ; \omega$ 为频率与 $2 \pi$ 的乘积 $\left(\mathrm{d}^{-1}\right) ; a$ 为水体热扩散系数 $\left(\mathrm{L}^{2} / \mathrm{T}\right) ; t_{0}$ 为一年开始 后, 到春夏之交时刻 (即气温等于年平均气温的时刻) 的天数 (d). 式 (5) 就是温跃层水温剖面随季节变化的 理论近似, 即温度振幅随深度变小, 当深度很大时水温与平均气温几乎相同.

利用式 (5) 描述温跃层的季节性变化必须有气象资料. 中国地质大学 (北京) 在苏木巴润吉林湖边安装 了气象仪器, 只有 1 年左右的观测资料, 显示气温的变化与中泉子气象站 (距离巴丹吉林沙漠最近的气象 站) 的同期监测结果基本一致. 为得到多年平均状态的结果, 本文使用中泉子气象站 1957-1999 年的气温 数据 ${ }^{[23]}$, 得到 $T_{0}=8.9^{\circ} \mathrm{C}, A=17.4^{\circ} \mathrm{C}, t_{0}=98.9 \mathrm{~d}, \omega=2.0 \times 10^{-7} \mathrm{~d}^{-1}$. 另外, 苏木巴润吉林的水化学成分以 $\mathrm{Na}^{+}$为主要阳离子, 以 $\mathrm{Cl}^{-}$为主要阴离子 ${ }^{[3]}$. 根据氯化钠水溶液热扩散系数的研究结果 ${ }^{[24]}$, 结合实测的湖水 矿化度值, 可初步确定温度扩散系数的取值为 $a=1.5 \times 10^{-7} \mathrm{~m}^{2} / \mathrm{s}$, 即 $0.013 \mathrm{~m}^{2} / \mathrm{d}$. 将这些参数代人式 (5) 可 以推测不同季节温跃层水温随相对深度 (相对混合层底部的深度) 的变化.

9 月份温跃层实测温度与理论推算结果的拟合情况表明 (图 4a), 温跃层顶面深度为 $6.67 \mathrm{~m}$ 时拟合最 佳, 相关系数达到 0.94 , 说明模型是可靠的. 由此进一步推测春 ( 3 月)、夏 ( 6 月)、秋 ( 9 月)、冬 (12 月) 各个 季节的温跃层水温剖面 (图 4b), 可见春季和冬季呈现逆温特征, 即温度总体上随深度的增加而增大; 夏季 和秋季呈现正温特征, 温度总体上随深度的增加而减小. 这些推测结果与前人研究 ${ }^{[15,20]}$ 发现的规律较为一
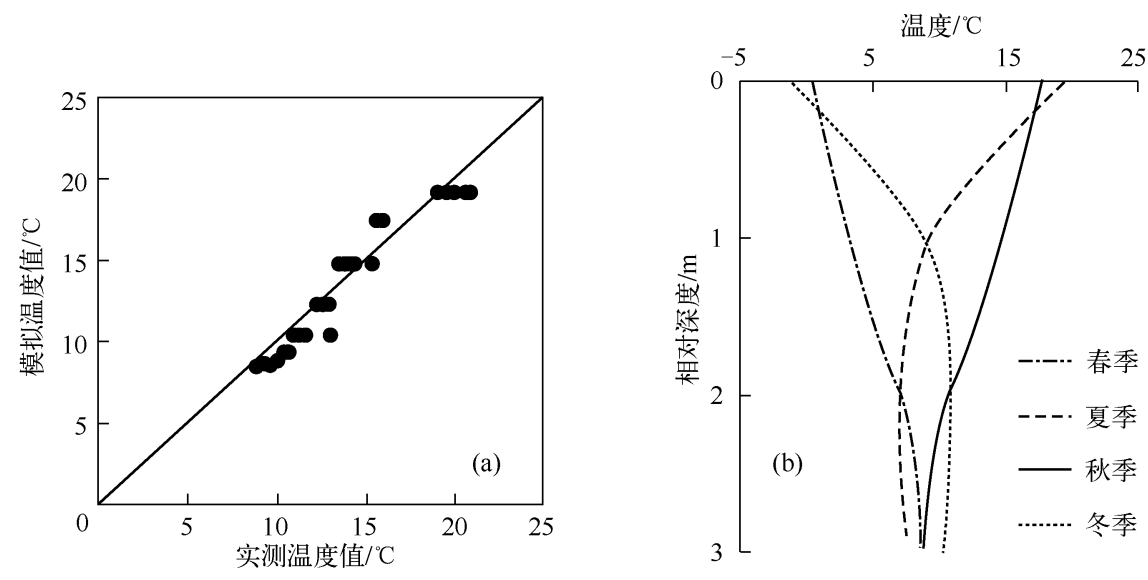

图 4 温跃层温度变化的模型推测 : (a) 9 月份模拟值与实测值拟合图; (b) 不同季节温度剖面模拟结果

Fig. 4 The change in temperature in thermocline speculated by the model: (a) simulation versus observation for temperature in September; (b) the simulation results of temperature profile in different seasons 
致. 图 4b 还显示出相对深度 $3 \mathrm{~m}$ 以下水温趋于稳定, 季节性变化幅度小于 $3^{\circ} \mathrm{C}$, 这意味着湖底的温度近似为 多年平均气温. 不过, 混合层和温跃层的厚度都会随季节变化, 图 4b 并不完全能够代表实际情况, 真实温度 剖面的季节性变化还有待进一步开展野外调查.

虽然式 (5) 忽略了地下水排泄引起的热量传递, 却能够很好地解释湖底 9 月份低温区的形成. 这说明苏 木巴润吉林夏季湖底的低温区对地下水的排泄并不具有实质性的指示意义,也从另一个角度说明地下水排 泄所伴随的热量传递不足以对湖水温度剖面产生可观的影响.

\section{3 化跃层对地下水排泄的指示作用}

在混合层以下,苏木巴润吉林盐分的分布并不像温度的分布那样规则, 表现出较强的空间变异性. 比较 突出的是在剖面东部的湖底附近出现矿化度的异常低值区, 形成了化跃层, 其 TDS 值不到混合层平均 TDS 值的一半. 笔者用 TLC 温盐深计对 W7 孔中的地下水进行了观测, 其电导率只有 $1.376 \mathrm{mS} / \mathrm{cm}$, 说明地下水 矿化度小于 $1 \mathrm{~g} / \mathrm{L}$. 因此, 靠近湖底的湖水矿化度异常低值区很有可能指示了地下淡水的集中排泄点或排泄 带, 即可能存在湖底泉. 当地下水在湖底集中排泄时,混合作用就可以降低局部湖水的矿化度,地下水排泄 量越大, 盐分稀释作用就越强. 笔者判断图 3 中的 $\mathrm{A}$ 曲线就是这种稀释作用的结果, 主要发生在靠近东岸的 湖底.

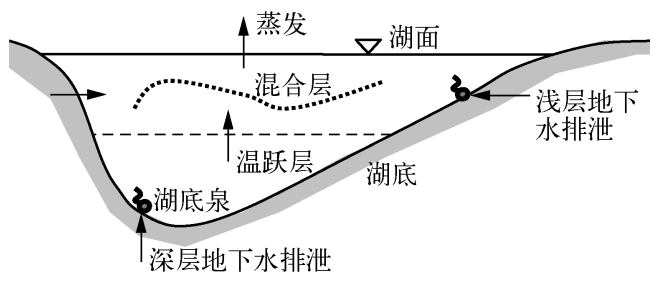

图 5 巴丹吉林沙漠盐湖的水流概念模型

Fig. 5 The conceptual model of flow in salt lakes in the Badain Jaran Desert

在巴丹吉林沙漠,地下水以泉水方式向湖泊排泄 是普遍现象 ${ }^{[25]}$, 湖底泉也屡见不鲜. 例如, 苏木吉林 的北部水体较浅,离湖岸约 $3 \mathrm{~m}$ 处的湖底有多处泉水 翻涌, 形成上部直径 $4 \sim 5 \mathrm{~m}$ 的倒锤形坑, 最深约 $1.3 \mathrm{~m}$, 坑底的湖水 TDS 显著低于浅层湖水. 本文把相 对湖面深度 $5 \mathrm{~m}$ 以上的地下水称为浅层地下水, 把更 深部位的地下水称为深层地下水. 因此, 苏木吉林肉 眼所见的湖底泉是浅层地下水集中排泄的直观表现， 而苏木巴润吉林盐分剖面所显示的湖底泉属于深层 地下水集中排泄的表现. 浅层、深层地下水的排泄与 湖水运动状态之间的关系用图 5 来概括. 当深层地下 水排泄到湖底后, 将形成向上的水流, 最终汇人到混合层, 并通过蒸发转变为大气水. 从这一点看, 其实温跃 层的湖水并非完全静止, 总体上应该有向上运动的趋势, 只不过由于过水断面很大, 平均流速很小, 远小于 湖面的蒸发强度 (不足 $10 \mathrm{~mm} / \mathrm{d}$ ). 这样缓慢的流动不会对混合层产生明显影响. 深层地下水排泄不一定就 发育在温跃层,也可能发育在混合层,但可能由于混合作用强烈而无法通过盐分剖面揭示出来.

盐湖化跃层的形成并不一定都是地下水排泄造成的, 与盐湖的具体环境有关. 青藏高原的错尼湖存在 浅层水温低、深层水温高的温度分层现象 ${ }^{[26-27]}$, 同时也存在浅层盐度低、深层盐度高的化学分层现象 ${ }^{[27]}$. 郑 绵平等 ${ }^{[27]}$ 提出这是卤水太阳池效应造成的, 与过去认为的地下热水排泄 ${ }^{[26]}$ 关系并不大. 本研究在苏木巴润 吉林观察到的水温和盐分分层特征与错尼湖存在很大差异,显然形成机理也不同.

\section{4 结论}

根据典型盐湖温度和盐度的剖面观测结果,巴丹吉林沙漠盐湖尽管水深不大,但可以发育混合层和温 跃层, 温跃层近似满足静止水体的热传导条件. 靠近湖底位置可以观测到矿化度异常低值区, 形成化跃层, 很可能指示了地下水在湖底集中排泄所形成的湖底泉.

本研究只对苏木巴润吉林进行了剖面扫描测量, 时间也集中在 9 月份, 这种有限的观测远不足以揭示 沙漠盐湖的水动力条件及其与地下水相互作用的全部特征. 这些盐湖是否全部有温跃层? 水体结构如何随 季节变化? 化跃层与湖底泉的流量有什么关联? 种种更加深人的问题有待于通过进一步的观测研究加以 解决.

\section{5 参考文献}

[1] 朱震达,吴 正,刘 恕等. 中国沙漠概论. 北京:科学出版社, 1980:73-76. 
[2 ] 陈建生,赵 霞, 盛雪芬等. 巴丹吉林沙漠湖泊群与沙山形成机理研究. 科学通报, 2006,51(23):2789-2796.

[ 3 ] 杨小平. 巴丹吉林沙漠腹地湖泊的水化学特征及其全新世以来的演变. 第四纪研究,2002,22(2):97-104.

[4] 丁宏伟,王贵玲. 巴丹吉林沙漠湖泊形成的机理分析. 干旱区研究,2007,24(1):1-7.

[ 5 ] 马妮娜, 杨小平. 巴丹吉林沙漠及其东南边缘地区水化学和环境同位素特征及其水文学意义. 第四纪研究, 2008, 28 (4):702-711.

[ 6 ] Ma JZ, Edmunds WM. Groundwater and lake evolution in the Badain Jaran Desert ecosystem, Inner Mongolia. Hydrogeology Journal, 2006,14(7) : 1231-1243.

[7] 马金珠,黄天明,丁贞玉等. 同位素指示的巴丹吉林沙漠南缘地下水补给来源. 地球科学进展, 2007,22(9): 922-930.

[ 8 ] Gates JB, Edmunds WM, Darling WG et al. Conceptual model of recharge to southeastern Badain Jaran Desert groundwater and lakes from environmental tracers. Applied Geochemistry, 2008,23(12):3519-3534.

[ 9 ] 陈建生, 赵 霞, 汪集昒等. 巴丹吉林沙漠湖泊钲华与根状结核的发现对研究湖泊水补给的意义. 中国岩溶, 2004, $23(4): 277-282$.

[10] Chen JS, Li L, Wang JY et al. Groundwater maintains dune landscape: A remote water source helps giant sand their ground in a windy desert. Nature, $2004, \mathbf{4 3 2}: 459-460$.

[11] 赵 霞,陈建生. 相似优先比法研究巴丹吉林沙漠及周边地区地下水补给. 湖泊科学, 2006,18(4):407-413.

[12］陆 芗,王乃昂,李贵鹏等. 巴丹吉林沙漠湖泊水化学空间分布特征. 湖泊科学,2010,22(5):774-782.

[13］朱金峰,王乃昂,李卓仑等. 巴丹吉林沙漠湖泊季节变化的遥感监测. 湖泊科学, 2011,23(4):657-664.

[14] 张振瑜,王乃昂, 吴 月等. 1973-2010 年巴丹吉林沙漠腹地湖泊面积空间变化的遥感分析. 湖泊科学, 2013,25 (4) :514-520.

[15] 陆 莹. 巴丹吉林沙漠湖泊水化学时空分布特征及其成因初探 [学位论文]. 兰州: 兰州大学,2012.

[16] Sorensen JA, Glass GE. Ion and temperature dependence of electrical conductance for natural waters. Analytical Chemistry, $1987, \mathbf{5 9}(13):$ :1594-1597.

[17] Hayashi M. Temperature-electrical conductivity relation of water for environmental monitoring and geophysical data inversion. Environmental Monitoring and Assessment, 2004 ,96(1/2/3):119-128.

[18] 胡汝䩀, 姜逢清, 王亚俊等. 亚洲中部干旱区的湖泊. 干旱区研究, 2005,22(4):424-430.

[19] 胡汝瀷,姜逢清,王亚俊等. 论中国干早区湖泊研究的重要意义.干旱区研究,2007,24(2):137-140.

[20］王洪道,史复祥.我国湖泊水温状况的初步研究.海洋湖沼通报,1980,(3):21-31.

[21］王银珠,誉培民. 抚仙湖水温跃层的初步研究. 海洋湖沼通报,1982,(4) :1-9.

[22] 涂新斌,戴福初. 土体一维传热方程解析解及热扩散系数测定. 岩土工程学报,2008,30(5):652-657.

[23] 黄天明. 应用环境同位素研究巴丹吉林沙漠地下水补给来源 [学位论文]. 兰州: 兰州大学,2007.

[24] 汪 军,朱 䑣,杜 晖. 氯化钠水溶液热扩散系数的研究. 上海理工大学学报,2001,23(4):328-333.

[25] 王 涛. 巴丹吉林沙漠形成演变的若干问题. 中国沙漠, 1990,10(1):29-40.

[26] 郑喜玉,张明刚,徐 昶等. 中国盐湖志. 北京:科学出版社,2002:61-62.

[27] 郑绵平,齐 文. 我国盐湖资源及其开发利用. 矿产保护与利用,2006,(5):45-50. 